\title{
Shock Loading-Unloading Mechanism in Rockburst Shear Fractures in Quartzite Causing Genesis of Polyhedral Sub-Particles in the Fault Gouge
}

\author{
B.G. Tarasov University of Western Australia, Australia \\ W.D. Ortlepp SRK Consulting, South Africa
}

\begin{abstract}
The presence of polyhedral sub-particles in dynamically-formed shear zones in quartzite is a specific manifestation of a very complicated and still enigmatic mechanism of shear fracture development. The existence of these sub-particles allows disclosure of one important feature of this mechanism. Comprehensive analysis of the geometrical shape of the sub-particles gave reason to conclude that the most plausible explanation of their formation is shock unloading taking place in the fracture zone. At the same time the fact that a relatively minute and very strong quartz grain can be disrupted into elemental subparticles of approximately 25 micrometres in size must indicate the presence of enormous amount of energy within the grain before the shock unloading. This energy can be provided, in particular, by shock loading preceding the shock unloading.

The paper discusses a new shear rupture mechanism which can provide the combination of extreme dynamic compressive loading followed by shock unloading within some special zones of the fault. According to this mechanism a general fault develops as a cascade of segments triggered in series one after another. Interaction and linkage of the segments propagating toward each other at a relative speed comparable with shear wave speed can cause shock-like loading-unloading impulses necessary for the particle formation due to specific structure of linkage zones.
\end{abstract}

\section{Introduction}

This paper discusses a new version of the shear rupture mechanism associated with formation of polyhedral sub-particles within the rupture zone in quartzite. The fact of the sub-particle presence and possible mechanisms of their formation were earlier described by Ortlepp, 1992, 1999, 2001; Ortlepp et al., 2005. A scanning electron microscope (SEM) photograph in Figure 1 illustrates the particle configuration (the photograph made by Gay, (1979). The intriguing fact is that these particles are formed due to fragmentation of a quartz grain into elemental sub-particles having extraordinary uniformity in size and the near-perfect crystal-like shape. Such particle geometry gave reason to suppose that the most plausible explanation of their formation is shock unloading taking place in the fracture zone.

At the same time the fact that a relatively minute and very strong quartz grain can be disrupted into elemental sub-particles of approximately 25 micrometres in size must indicate the presence of enormous amount of energy within the grain before the shock unloading. Results of experimental and theoretical studies of dynamic behaviour of materials show that a shock compressive loading can provide the material with additional kinetic energy not available quasi-statically necessary for the material fragmentation during the following shock unloading. This question is discussed, in particular, in a book by Meyers, 1994. Hence, the combination of impact compressive loading and following instantaneous tensile relief is the most likely condition for the sub-particle formation.

The question is what mechanism of the fault development can be responsible for such character of the stress variation? Presently available version of such a mechanism is the fault asperity interaction during spontaneous fault displacement (Lomnitz-Adler, 1991; Melosh, 1996). This mechanism was accepted as a possible mechanism causing the sub-particle generation (Ortlepp, 1992, 1999; Ortlepp at al., 2005). However, despite the extreme violence of the rupture process as a whole the fault displacement occurs at relatively low speed - which is about a number of meters per second (McGarr, 2001). Such speed is not 
sufficient for quick change-over from loading to unloading conditions to generate intensive tensile waves within the rock body.

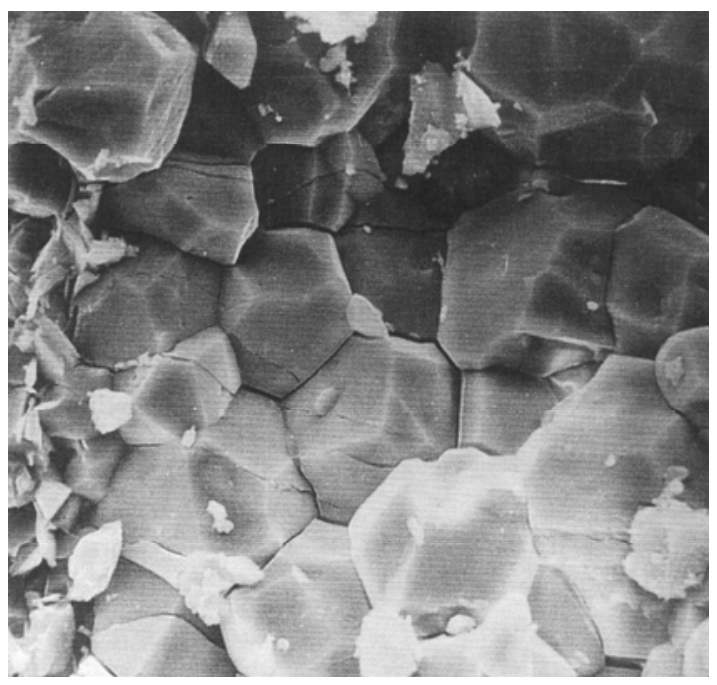

Figure 1 SEM micrograph showing a quartz grain disrupted into elemental polyhedral sub-particles (from Ortlepp, 1992)

Recently a new shear rupture mechanism was proposed (Tarasov, 2007) according to which a general fault develops as a cascade of segments triggered in series one after another. Interaction and linkage of the segments propagating toward each other at a relative speed comparable with shear wave speed can cause extremely powerful and shock-like loading-unloading impulses within linkage zones. The paper discusses this mechanism. The general concept of the new shear rupture mechanism is presented in the keynote address of this seminar and entitled 'Paradoxical features of primary shear fractures and general faults' (Tarasov and Randolph, 2007a).

\section{Mechanism of formation of sub-particles}

Figure 1 presents a SEM micrograph of the internal structure of a quartz grain from fault gouge from 1974 ERPM \# 1 brittle shear showing disruption into elemental polyhedral sub-particles. Shear zone was associated with $\mathrm{M}_{\mathrm{L}}=2.1$ rockburst of 23 September 1970 (Ortlepp, 1992). Importantly, despite the extraordinary uniformity in size and the near-perfect crystal-like shape of the particles the morphology was not crystalographically possible (J. Lurie, 1991). Of all possible geometrical shapes, the rhombic dodecahedron, which appeared to most closely approximate the particle shape, has the unique attribute that it fills 3-dimesional space completely, with the largest number of facets and the least possible surface area. It was postulated that pervasive isotropic tensile shock-loading could cause an ideally-elastic, brittle material to disrupt into elemental particles that would each require the minimum necessary expenditure of energy to disassociate itself from its neighbouring particles. Quartz has the appropriate mechanical properties to respond in this way and, if it did so, the resulting elemental particles would, ideally, be rhombic dodecahedra.

Figure 2 illustrates a possible failure mechanism causing such structure formation (Ortlepp, 1992). A small portion of the incipiently failing rock comprising of a quartz grain, or several adjoining grains, is momentarily over-compressed hydrostatically, accumulating elastic strain energy. The stress-strain curve would increase linearly to some considerably elevated value. If allowed suddenly to relax instantaneously and completely, the internal fabric of the grain would experience a uniform, isotropic tensile 'shock' due to elastic re-bound. Small volume elements (illustrated as incipient dedocahedra in Figure 2) would tend to expand and acquire some inertial momentum away from one another. The stress-strain response at potential interfaces would rapidly decrease (along the linear portion of the graph), overshoot the zero-strain point and continue into the tensile domain. The 'rebound' would extend beyond the critical tensile strain limit for quartz and direct tensile fracturing would ensue simultaneously along planes perpendicular to each of the isotropic tensile stress vectors. 


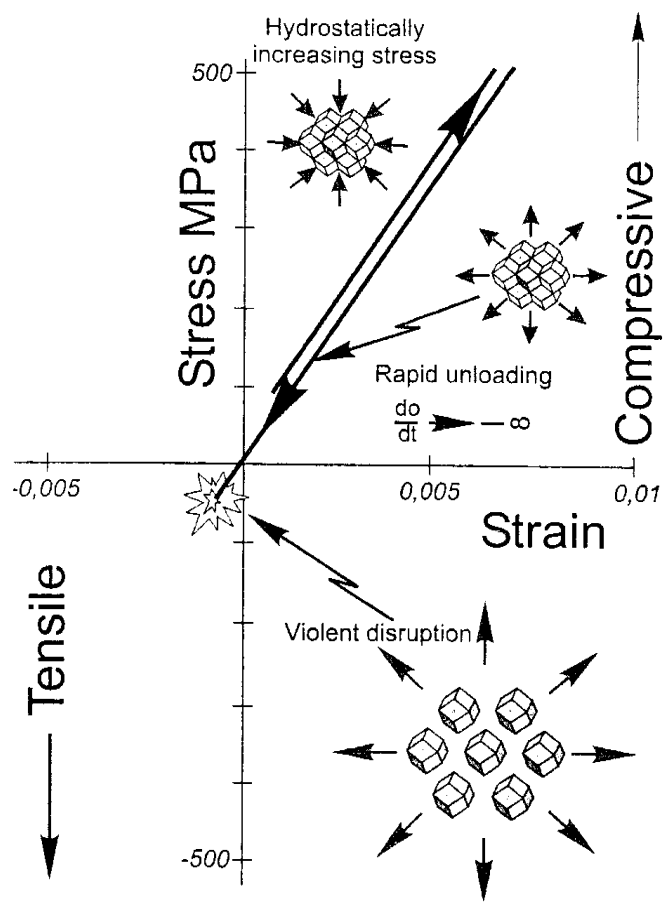

Figure 2 Stress-strain graph illustrating dynamic overloading followed by instantaneous 'shock' unloading leading to violent disruption of quartz grain (from Ortlepp at al., 2005)

In a perfect material (i.e. one with no defects even on a molecular scale), there would be sets of twelve stress vectors, uniformly distributed and directed outwards from nuclei uniformly spaced in a 3-D lattice grid. These geometrical requirements are logically inferred from the fact that the twelve perpendicular places along which the tensile fracturing would extend, must necessarily form the twelve facets of a rhombic dodecahedron. This condition follows from the fact that this particular geometric form is the one that uniquely fills space completely with the smallest surface area. In other words such a configuration is the most energy-efficient way of dividing three-dimensional space (Aste and Weaire, 2000).

\section{Shock loading-unloading mechanism in faults}

\subsection{Speed of the blow delivery}

Hopkinson, $(1910,1914)$, who is a pioneer of study of dynamic material failure due to tensile stresses generated by the interaction of release waves, pointed out: 'Iron or steel may become brittle under sufficiently great forces applied for very short times. No ordinary hammer blows will do, but the blow delivered by a high explosive is quick enough. The fact that a blow involving only pressure may, by the effects of wave action and reflection, give rise to tension equal to or greater than the pressure applied, often produces curious effects.'

Energetically dynamic loading provides the body with the additional kinetic energy not available quasistatically. Quasi-static fracture often only breaks a loaded body into two parts. One of the most important aspects of dynamic fracture is the sequential character leading to fragmentation. At the end of the fracturing sequence, the body is divided into many parts. The size of fragments is a function of strain rates, i.e. blow speed delivery (Meyers, 1994; Grady and Kipp, 1980; Grady, 1982).

What speed of the blow application should be sufficient for the sub-particles generation? Ordinary hammer blows can be applied with a maximum speed of a few meters per second. Similar speed corresponds also to dynamically displacing faults. At the present, blows generated by the asperity interaction during spontaneous fault displacement are treated as a possible mechanism causing loading-unloading conditions for the subparticle generation. By analogy with Hopkinson's experiments we can conclude that blows generated by 
interacting asperities are not quick enough to produce reflecting tensile stresses sufficient for the sub-particle formation in such strong material as quartz. To provide this effect the speed of blow application should be at list comparable with compressive wave speed in gas which takes place at explosive used by Hopkinson in his experiments.

\subsection{Analysis of fault zone where the sub-particles were formed}

To understand the loading-unloading mechanism responsible for the sub-particle formation we need to analyse in more details the fracture zone where the sub-particles were detected. The finely-crushed material of the fault-filling involving the polyhedral sub-particles was collected for the scanning electron microscope studies from a fault zone adjacent to a junction connecting two overlapping fractures similar to that shown in Figure 3. Photographs here show linkage zones at different degree of their development connecting two left stepping fractures. The junction in the photographs is one of many junctions involved into the general fault for connection of an echelon of fractures (fault segments). The junction zone is represented by a block structure formed due to intensive tensile cracking which is a typical structure of any shear fracture. Direction of the fault displacement is indicated by open arrows. Solid arrows show approximately directions of major and minor stresses in the field determined on the basis of tensile crack orientation. It is known that tensile cracks have tendency to grow along the major stress. We should notice, however, that within the linkage zone the local stress orientation can be different as compared with the far field stress due to the influence of the segments. Furthermore, during the fault displacement blocks located between tensile cracks can change significantly their orientation due to rotation. So, these features of the fault structure should be taken into account at estimation of the far field stress directions.

a

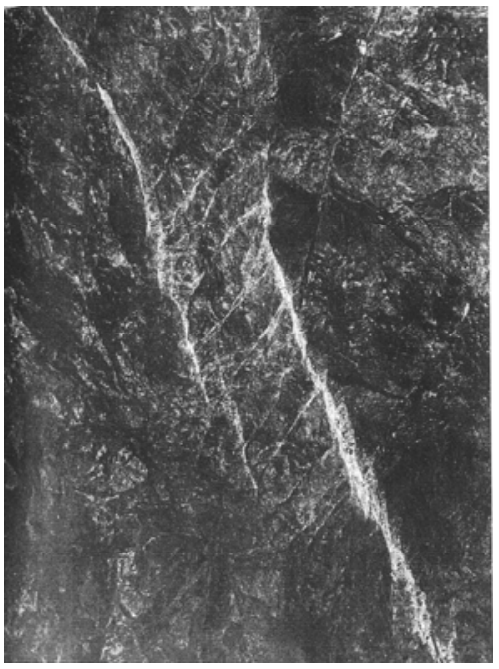

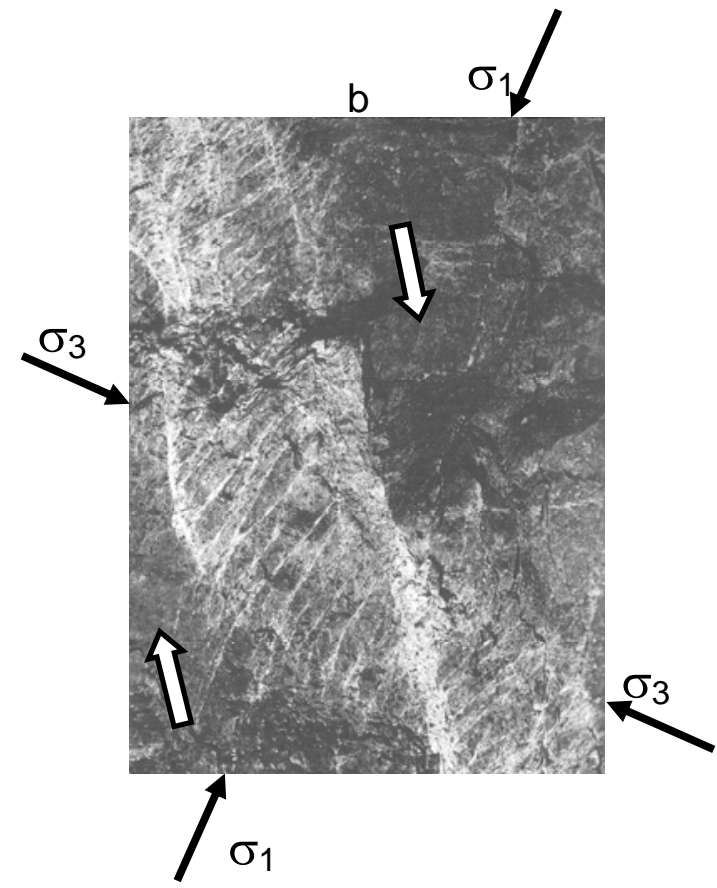

Figure 3 Linkage zones between two overlapping fractures at different degree of their development (from Ortlepp, 1997)

Figure 4 illustrates the state of stress and secondary fracturing near the linkage zone of two left step segments (from Segall and Pollard, 1980). The applied far field stresses and direction of shear are indicated in the figure. The junction geometry here (left step) is similar to that for the junction in Figure 3. The difference is that in Figure 4 segments are separated. Segall and Pollard pointed out that this is the minimum separation that allows sliding to occur over the entire segments; smaller separation leads to sticking near the segment ends. Distributions of mean stress and maximum shear stress are shown in Figures $4 \mathrm{a}$ and $4 \mathrm{~b}$ correspondingly. Figures $4 \mathrm{c}$ shows contour of the magnitude of maximum tension $\mathrm{s} 3=0$. Contour of shear failure condition $\mathrm{F}$ is shown in Figure 4d. Tick marks indicate direction of minimum compression s3. In the far field, $\mathrm{s} 3$ is $60^{\circ}$ from the segment direction. 


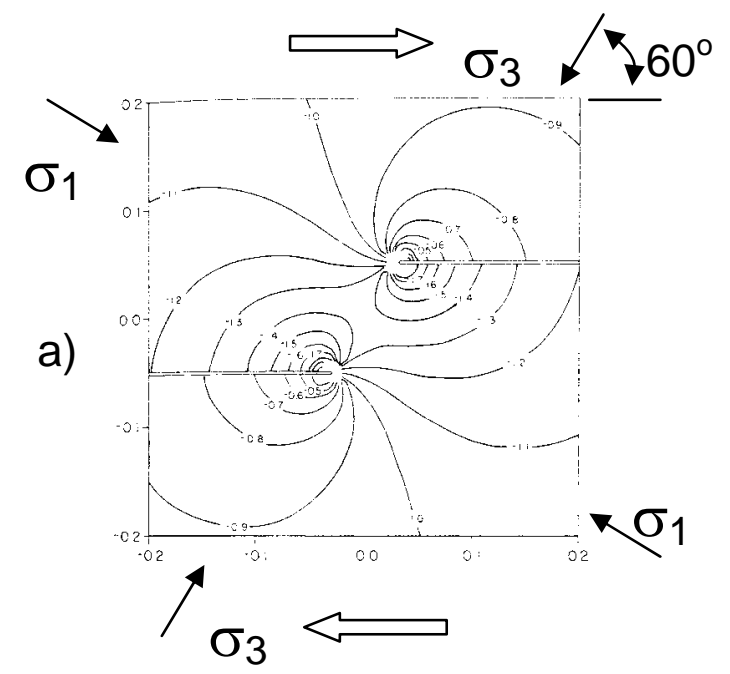

b)

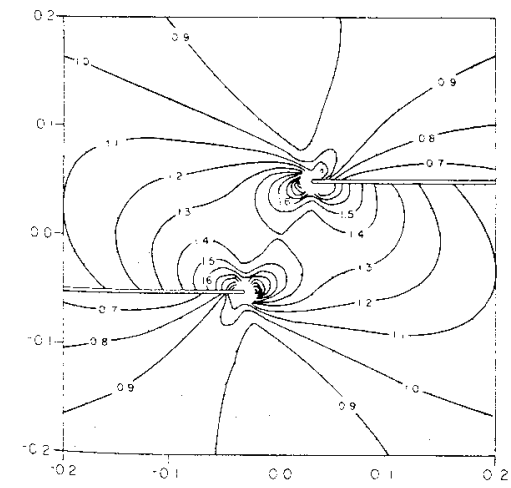

c)

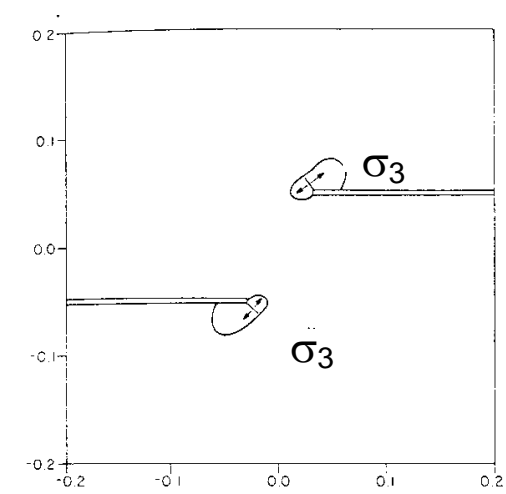

d)

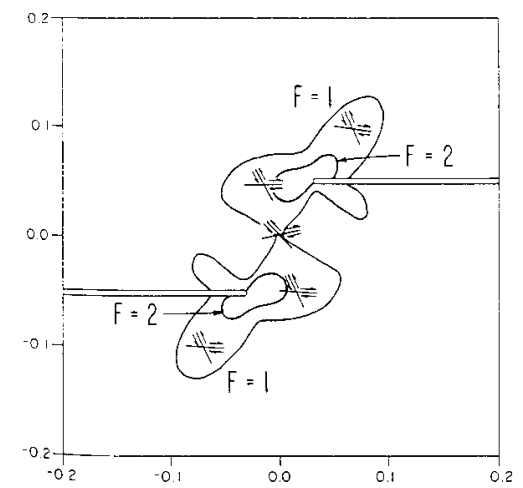

Figure 4 State of stress and secondary fracturing near the linkage zone of two left step segments. Distribution of a) mean stress and b) maximum shear stress. c) Contour of the magnitude of maximum tension $\sigma_{3}=\mathbf{0}$. d) Contour of shear failure condition F. (from Segall and Pollard, 1980)

The following important conclusions are drawn from this modelling:

- Mean stress is everywhere compressive and the compression increases to 1.4 times the background value in the region between the segments. In the region adjacent to, but outside, the segments the mean stress is less than that in the far field.

- The increase in maximum shear is restricted to the region between the segments where it increases to 1.4 times the background value. The region outside the segments is subject to a decrease in maximum shear.

- Orientation of s3 between the segments departs from the far field orientation due to the presence of the segments. It is rotated counterclockwise by about $10^{\circ}$.

- Short tensile cracks may form toward the outside of the step, relieving the stress in this region and focusing any secondary shear fracturing ahead of, and between, the segments.

- At the lengthening of the segments left lateral secondary shear fractures may form within the step oriented at about $60^{\circ}$ to the lengthened segments.

- The line linking the segment ends is nearly perpendicular to the local maximum compression and is an unfavourable orientation for secondary fracture. 


\subsection{Fault segmentation}

The model discussed above analyses the displacement of fault consisting of a number of existing segments and does not consider the reason for the fault segmentation. It is important to accentuate that despite very intensive study of the nature of segmentation during the few last decades (Clayton, 1966; Sharp and Clark, 1972; Segall and Pollard, 1980, 1983; Granier, 1985; Sibson, 1985, 1986; Harris and Day, 1993; Burgmann at al., 1994; Vermilye and Scholz, 1999; Scholz, 2002; Poliakov et al., 2002; Rice et al., 2005) no consensus of opinion has been reached regarding physical mechanisms responsible for this phenomenon. Examples of existing mechanisms are below:

- Segmentation as result of the linkage of pre-existing segments.

- Segments as an echelon of mode-I cracks involved in the structure of general fault by analogy with tensile cracks in mode-II (or mode III) primary fractures.

- Segmentation as result of separation of continuous fault when it encounters masses of more resistant rock.

- Initiation of rupture on a branching fault due to stresses around dynamically propagating rupture tip located off the main fault plane.

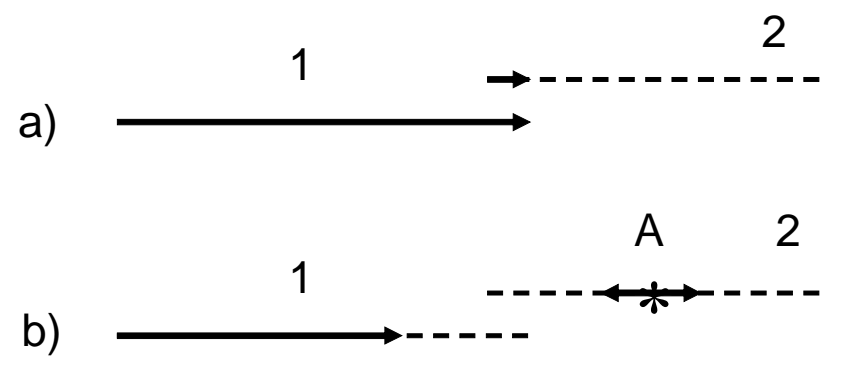

Figure 5 Interaction between preceding and subsequent segments on the fault in accordance with a) common knowledge and b) new approach (from Tarasov, 2007)

Recently a new fault development mechanism was proposed (Tarasov, 2007; Tarasov and Randolph, 2007b) according to which the segmentation is the result of advanced triggering of new fractures propagating bilaterally towards the current fracture and in the opposite direction. A fault in this interpretation is a cascade of segments triggered in series one after another. The fundamental difference between the existing and the new approaches is illustrated in Figure 5. In accordance with existing concepts the fracture process in segment- 2 can be initiated only after the fracture in segment- 1 has reached segment-2 (Figure 5a). When segment-2 is initiated, segment-1 stops propagating further. In accordance with the new concept the propagating fracture-1 due to stress transfer initiates a new one at point A located at some distance ahead of the current fracture. The new fracture propagates bilaterally towards the current fracture and in the opposite direction. When two approaching fractures meet they normally form a step over with different linkage mechanisms connecting the segments (Tarasov, 2007; Tarasov and Randolph, 2007b). A linkage mechanism connecting left stepping segments is considered below.

\subsection{Linkage mechanism for left stepping segments}

Figure 6 illustrates different phases of the linkage development between two fractures (segments) propagating toward each other. Figure 6a shows a zone of the future collision (quadrangle) and indicates directions of the stress application. Direction of the fault displacement is shown by open arrows. Figures $6 \mathrm{~b}$ and $6 \mathrm{c}$ show two situations at different approaching of the fractures. The fractures are represented by solid arrows. The quadrangle here is theoretically divided into two fragments (1and 2) pressing toward each other by applied stresses. The situation in Figure $6 \mathrm{c}$ corresponds to the situation discussed above in Figure 4 . The compressive stress within the linkage zone at this stage is $40 \%$ higher compared with far field stress. It should be accentuated that this stress concentration was calculated for static fracture conditions. It is known that stress around a dynamically propagating fracture is a function of the speed of propagation and can be significantly greater compared with the static conditions (Freund, 1990; Broberg, 1999; Poliakov et al., 2002; 
Rice et al., 2005). We should take into account also the fact that the relative speed of the approaching fractures is the double of the shear rupture speed. In idealized conditions of homogeneous materials the shear rupture can propagate intersonically (Rosakis et al., 1999, 2006; Rosakis, 2002). In natural conditions for rocks the reported rupture speed is normally subsonic (Kanamory and Brodsky, 2000). If we assume the fracture speed equal to $1500 \mathrm{~m} / \mathrm{sec}$, the approaching speed is $3000 \mathrm{~m} / \mathrm{sec}$. It means that the compression of the linkage zone is provided with such tremendous speed.

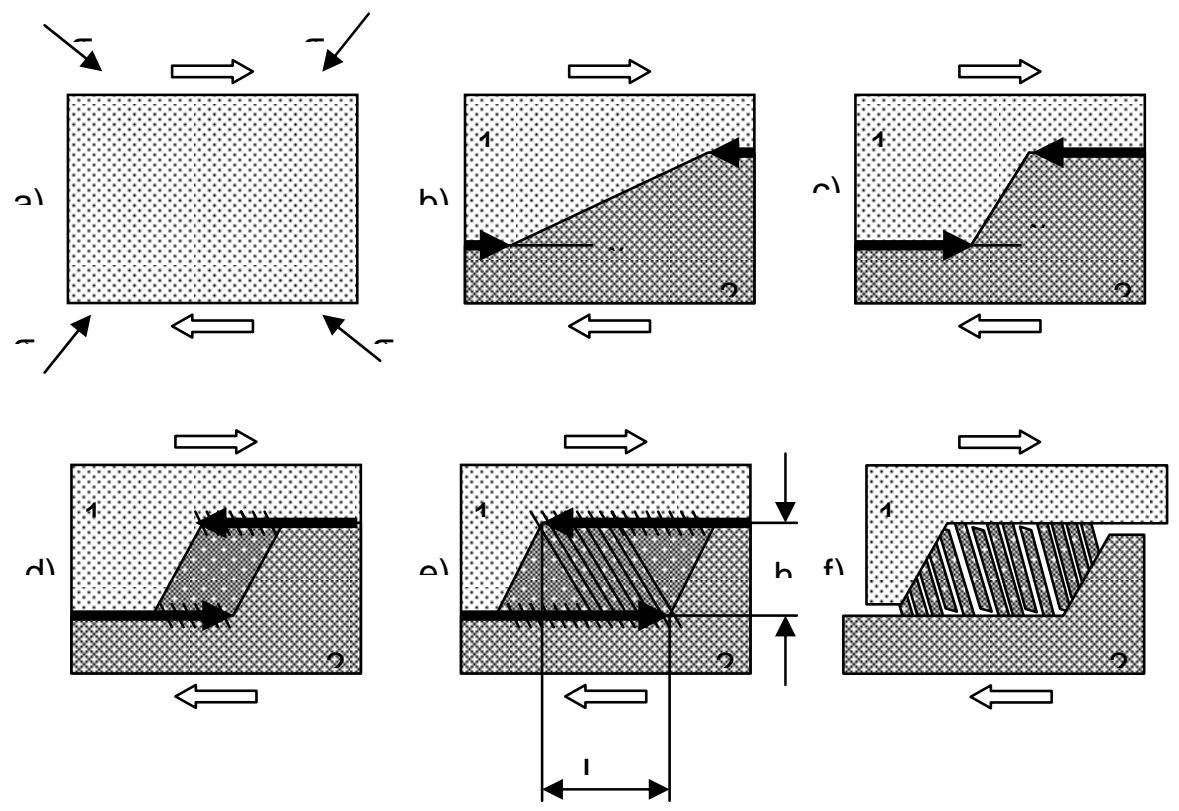

Figure 6 Mechanism of shock-like linkage of left stepping segments

At the further propagation of the fractures they confine a zone of overstressed rocks (Figure 6d). It is important that, in accordance with the Segall and Pollard study, the tensile fracture formation which can release the stress is suppressed within this zone. The only possibility is the creation of short tensile cracks formed toward the outside of the step (see Figure $4 \mathrm{c}$ and Figure 6d). When the extending overlapping zone reaches some critical length Lcr the nucleus tensile cracks located on the opposite fractures get a chance to be combined (Figure 6e). At this stage the overlapping zone turns into a relatively short and thick joining shear fracture consisting of an echelon of blocks, which is typical structure for any shear fractures (Figure 6f). $h$ indicates here the thickness of the joining fracture. The formation of the joining fracture and shear along it has the shock-like character. The rotation of blocks during the shear creates voids between blocks and unloads the shear fractures (segments) in areas adjacent to the linkage zone (joining fracture). The described mechanism provides extraordinary dynamic shock loading-unloading impulse capable to cause the sub-particle generation. Figure 7 illustrates that configuration of the real joining fractures for the left stepping segments formed in quartzite where the sub-particles were detected is similar to that shown in Figure $6 f$. This is an additional indirect verification of the validity of the proposed mechanism. 


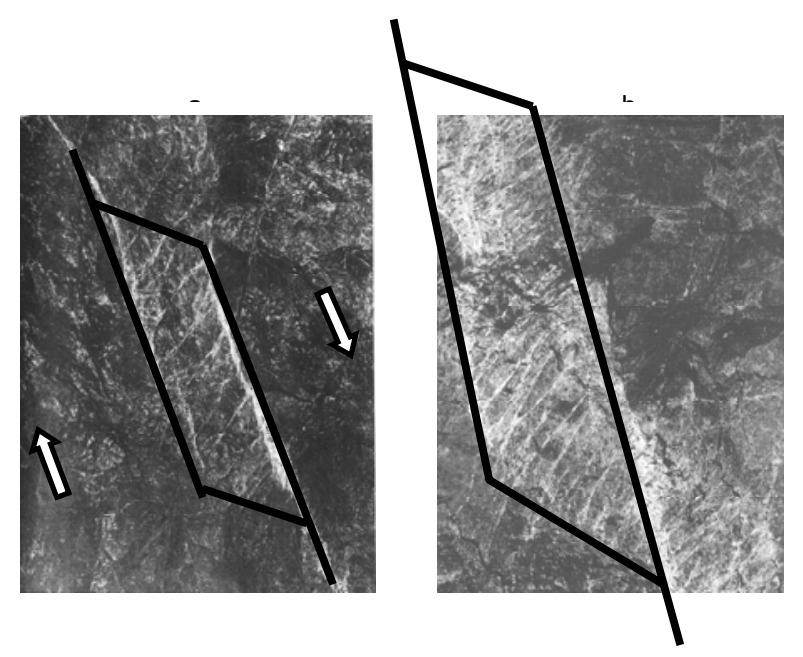

Figure 7 Illustration of approximate configuration of the overstressed zone within which the joining shear fracture was formed

\subsection{Spheroidal particles in the fault gouge}

The discussed mechanism is the source of momentary accumulation and dissipation of tremendous amount of energy. The shock compression of relatively small volume of rock at extremely high speed of the blow application $(3000 \mathrm{~m} / \mathrm{sec})$ can cause momentary temperature elevation. The following failure with the momentary creation of void within the initially solid material should produce high vacuum. The combination of these factors was proposed earlier as the source mechanism for creation of another sort of particles spherical particles observed in the ultra-fine gouge material of shear ruptures in quartzite (Ortlepp, 1997, 2001). Figure 8 shows photographs of such particles located in fault gouge of an induced brittle shear which resulted in a rockburst of $\mathrm{M}_{\mathrm{L}}=2.4$ on 30.01 .96 (sample by M. Grodner, SEM study by R. Armstrong). The gouge was collected from a linkage zone similar to that shown in Figure 7. Ortlepp pointed out that these particles are the preserved evidence of an extraordinary micro-phenomenon that entails some relatively low melting-point silicate mineral melting, vaporizing, condensing into minute droplets and freezing all in a few milliseconds of time.
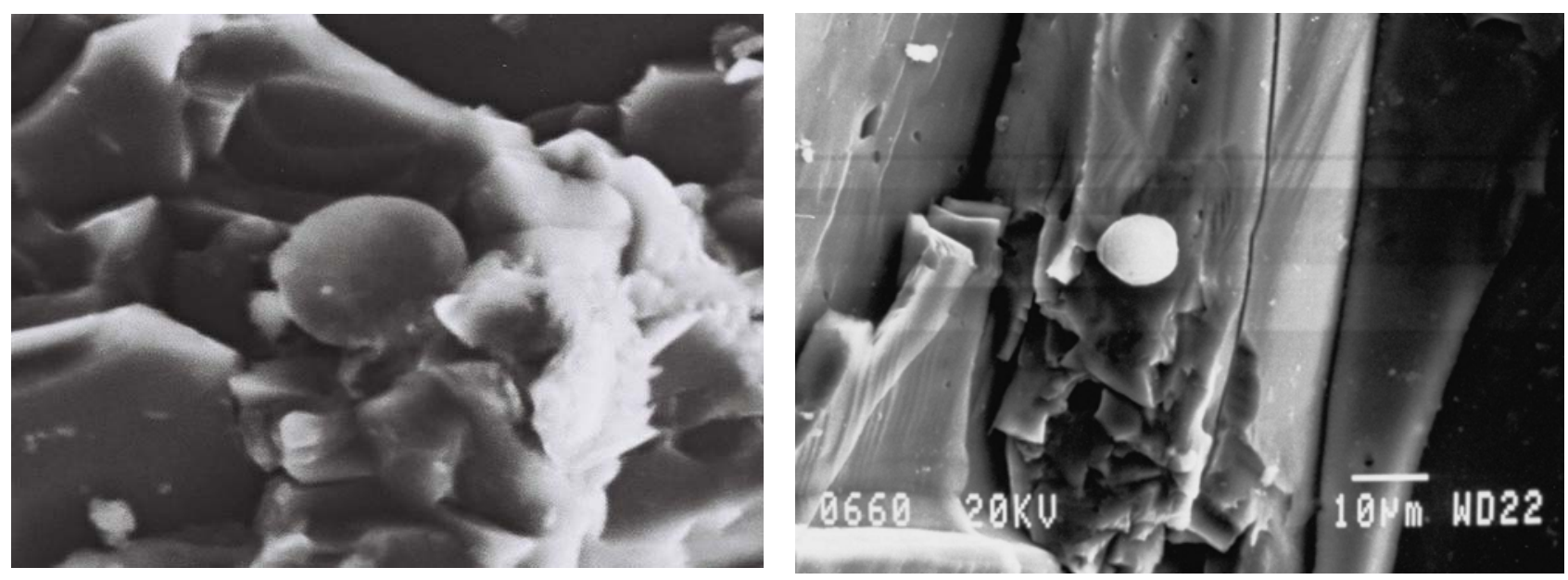

Figure 8 Spherical particles of silicate material observed in the ultra-fine gouge of shear rupture in quartzite (from Ortlepp, 2005) 


\section{Conclusions}

The failure mechanism discussed in the paper is based on an idea that the fault segmentation (which is a natural feature of general faults) is a result of advanced triggering of new fractures propagating bilaterally towards the current fracture and in the opposite direction. The paper shows that linkage of two left step approaching fractures (segments) propagating with relative speed comparable with shear wave speed, is accompanied by shock overstress of rock volume within the overlapping zone followed by shock-like energy release. The extremely high speed of the load application should cause momentary temperature elevation. A special joining fracture formed in the overlapping zone consisting of an echelon of rotating blocks creates voids within initially solid rock which should produce high vacuum. The combination of such factors as shock overstress, temperature elevation, shock-like energy release and high vacuum can cause formation of special particles (polyhedral sub-particles and spheroids) observed in the ultra-fine gouge material of shear ruptures in quartzite.

\section{References}

Aste, T. and Weaire, D. (2000) The puruit of perfect packing. IoP/Bookmark. Physics. www.bookmarkphysics.iop.org/ bookpge.htm2.

Broberg, K.B. (1999) Cracks and Fracture, London, Academic. 752 p.

Burgmann, R., Pollard, D.D. and Martel, S.J. (1994) Slip distributions on faults: effects of stress gradients, inelastic deformation, heterogeneous host-rock stiffness, and fault interaction, J. Struct. Geol. 16, pp. 1675-1690.

Clayton, L. (1966) Tectonic depressions along the Hase fault, a transcurrent fault in north Canterbury, New Zealand, New Zealand J. Geol. Geophys. Vol. 9, pp. 94-104.

Freund, L.B. (1990) Dynamic fracture mechanics, Cambridge, Cambridge University Press.

Gay, N.C. and Ortlepp, W.D. (1979) Anatomy of a mining-induced fault zone. Geol. Soc. Of America Bull. Part 1, Vol. 90, pp. 47-58.

Grady, D.E. and Kipp, M.E. (1980) Int. J. Rock Mech. Min. Sci., Vol. 17, p. 147.

Grady, D.E. (1982) J. Appl. Phys., Vol. 55, p. 322.

Granier, T. (1985) Origin, damping and pattern of development of faults in granite, Tectonics, Vol. 4, pp. 721-737.

Harris, R.A. and Day, S.M. (1993) Dynamics of fault interaction: parallel strike-slip faults. J. Geophys. Res., Vol. 98, pp. 4461-4472.

Hopkinson, B. (1910) Scientific Papers, Cambridge University Press, London.

Hopkinson, B. (1914) Trans. Roy. Soc., London, 213A, p. 437.

Kanamori, H. and Brodsky, E. (2001) The physics of earthquakes, Phys. Today, Vol. 54, pp. 34-40.

Lonnitz-Adler, J. (1991) Model for steady-state friction. J. Geophys. Rev. 96, No. B4, pp. 6121-6131.

Lurie, J. (1991) Private communication, Dr. J. Lurie of Technikon, Witwatersrand, Johannesburg. South Africa (Fax 011-402-0475).

McGarr, A. (2001) Control of strong ground motion of mining-induced earthquakes by the strength of the seismogenic rockmass. $5^{\text {th }}$ Int. Symp. on Rockbursts and Seismicity in Mines - RaSiM 5, SAIMM, Johannesburg, 2001.

Melosh, H.J. (1996) Dynamical weakening of faults by acoustic fluidization. Nature, Vol. 379.

Meyers, M.A. (1994) Dynamic behaviour of materials. John Wiley \& Sons, Inc. 668 p.

Ortlepp, W.D. (1992) Note on fault-slip motion inferred from a study of micro-cataclastic particles from an underground shear rupture. PAGEOPH, Vol. 139, No. 3/4, pp. 677-695.

Ortlepp, W.D. (1997) Rock fracture and rockbursts. SAIMM Monograph Series, MJ, Johannesburg.

Ortlepp, W.D. (1999) Observation of mining-induced faults in an intact rock mass at depth. Int. J. Rock Mech., Vol. 37 , pp. 423-436.

Ortlepp, W.D. (2001) Thoughts on the rockburst source mechanism based on observations of the mine-induced shear rupture. $5^{\text {th }}$ International Symposium on Rockburst and Seismicity in Mines (RaSiM5), Johannesburg, South Africa, pp. 43-51.

Ortlepp, W.D., Armstrong, R., Ryder, J.A. and O'Connor, D. (2005) Fundamental study of micro-fracturing on the slip surface of mine-induced dynamic brittle shear zones. $6^{\text {th }}$ International Symposium on Rockburst and Seismicity in Mines Proceedings, Perth, Australia, March, 2005.

Poliakov, A.N.B., Domowska, R. and Rice, J.R. (2002) Dynamic shear rupture interactions with fault bends and offaxis secondary faulting, J. Geophys. Res. 107, No. B11, 2295, doi 10.1029/2001JB000572, ESE 6-1-6-18.

Rice, J.R., Sammis, C.G. and Parsons, R. (2005) Off-fault secondary failure induced by a dynamic slip pulse. Bull. Seismol. Soc. Am. Vol. 95, No. 1, pp. 109-134.

Rosakis, A.J., Samudrala, O. and Coker, D. (1999) Cracks faster than the shear wave speed. Science, Vol. 284, pp. 1337-1340.

Rosakis, A.J. (2002) Intersonic shear cracks and fault ruptures. Advances in Physics, Vol. 51, No. 4, pp. 1189-1257. 
Rosakis, A.J, Kanamori, H. and Xia, K. (2006) Laboratory earthquakes, Int. J. Fracture, Vol. 138, pp. 211-218. Scholz, C.H. (2002) The mechanics of earthquakes and faulting. Cambridge University Press.

Segall, P. and Pollard, D.D. (1980) The mechanics of discontinuous faults, J. Geophys. Res., Vol. 85, pp. 4337-4250.

Segall, P. and Pollard, D.D. (1983) Nucleation and growth of strike-slip faults in granite, J. Geophys. Res., Vol. 88, pp. 555-568.

Sharp, R.V. and Clark, M.M. (1972) Geologic evidence of previous faulting near the 1968 rupture on the Coyote Creek fault, U.S. Geol. Surv. Proof. Pap., Vol. 787, pp. 131-140.

Sibson, R.H. (1985) Stopping of earthquake ruptures at dilatational jogs. Nature, Vol. 316, pp. 248-251.

Sibson, R.H. (1986) Rupture interaction with fault jogs, Earthquake source mechanisms. S. Das, J. Boatwright and C.H. Scholz (eds), American Geophysical Union, Washington.

Tarasov, B.G. (2007) Intersonic shear rupture mechanism (submitted to Int. J. Rock Mechanics 12.02.2007).

Tarasov, B.G. and Randolph, M.F. (2007a) Frictionless shear at great depth and other paradoxes of hard rocks, Int. J. Rock Mechanics (in press).

Tarasov, B.G. and Randolph, M.F. (2007b) Paradoxical features of primary fractures and general faults. $4^{\text {th }}$ International Seminar on Deep and High Stress Mining (Deep Mining 07), Perth, Western Australia, 7-9 November 2007.

Vermilye, J.M. and Scholz, C.H. (1999) Fault propagation and segmentation: insight from the microstructural examination of a small fault. J. Struct. Geol., Vol. 21, pp. 1623-1636. 